\title{
Réplica - Acesso Livre: Caminho para Maximizar a Visibilidade da Pesquisa ${ }^{(1)}$
}

\section{Free Access: a Pathway to Maximizing the Visibility of Research}

Hélio Kuramoto*

Doutor em Ciências da Informação e da Comunicação pela Universite Lumiere

Lyon 2, França.

Coordenador Geral de Pesquisa e Manutenção de Produtos Consolidados do Ibict, Brasília/DF, Brasil.

*Endereço: Instituto Brasileiro de Informação em Ciência e Tecnologia, Coordenação Geral de Projetos Especiais, SAS Quadra 05, Lote 06, Bloco H, Setor de Autarquias Sul, Brasilia/DF, 70070-914.E-mail: kuramoto@ibict.br 
A informação científica é um insumo crucial para o desenvolvimento científico e tecnológico de um país. Esse insumo é resultado das pesquisas e estudos científicos realizados pelos pesquisadores, cujos estudos são em sua maioria financiados pelo setor público. Portanto, se esses resultados são obtidos por meio de um trabalho financiado com recursos públicos, a lógica e o bom senso indicam que os resultados deveriam ser de acesso livre. Mas, nos moldes da comunicação científica tradicional, isso não acontece.

A comunicação científica é realizada de várias formas. A apresentação dos resultados na forma oral é realizada em encontros, como as conferências, simpósios e outros eventos similares. A apresentação dos resultados na forma escrita é realizada por meio de revistas científicas, e hoje, com as tecnologias da informação e da comunicação, a informação científica ganha novas alternativas para maximizar a sua visibilidade e o seu acesso. Mas nem sempre a comunicação científica teve tantas facilidades.

\section{Origem da Informação Científica}

Segundo Meadows (1999), não se pode afirmar quando se começou a fazer pesquisa científica e, conseqüentemente, quando, pela primeira vez, realizou-se a comunicação científica. Mas, de acordo com o mesmo autor, as atividades que tiveram impacto na comunicação científica moderna tiveram início na antiga Grécia. Os gregos utilizavam a fala e a escrita para fazer a comunicação dos resultados de suas pesquisas. Os debates acadêmicos remontam à Academia, lugar na periferia de Atenas, onde as pessoas se reuniam, nos séculos IV e V a.C., para debater questões filosóficas. Da mesma forma, o simpósio era uma festa dos gregos em que debates e bebidas circulavam livremente.

Os gregos foram também os que mais contribuíram com a comunicação científica, utilizando a forma escrita, na qual se destacou Aristóteles, cujos debates foram precariamente conservados em manuscritos copiados repetidas vezes, influenciaram a cultura árabe e em seguida a Europa Ocidental. A análise e interpretação das idéias contidas nesses manuscritos contribuíram para o reavivamento do saber ocorrido entre os séculos XIV e XVI, época conhecida como Renascimento. A introdução da imprensa no século XV facilitou sobremaneira a comunicação científica, por meio de maior oferta e disponibilidade de textos impressos. Nessa época, evidentemente, nem todos os livros difundiam resultados 
de pesquisa, mas não havia dúvida quanto à sua importância para a difusão dos resultados de pesquisa. Um exemplo disso foi a publicação da obra que fundou a astronomia moderna, no ano de 1543 , De revoutionibus orbium coelestium (Das revoluções dos corpos celestes), de Copérnico. Outro exemplo foi a publicação da primeira obra moderna sobre anatomia humana, De humani corporis fabrica (Da estrutura do corpo humano) de Versálio. Assim, o surgimento da imprensa contribuiu, graças à sua capacidade de multiplicar os exemplares de um texto, para uma difusão melhor e mais rápida das pesquisas científicas.

A seguir, no início do século XVII, Francis André descreve o surgimento de uma ciência experimental moderna, marcada por personalidades como Galileu, Descartes, Kepler, entre outros. Assiste-se a um verdadeiro desenvolvimento colegial do saber, inicialmente, por meio de cartas manuscritas trocadas entre personalidades como Torricelli, Newton, Descartes e Leibniz, às vezes, no contexto de círculos intelectuais emergentes como a Academia Parisiense criada por Marin Marsenne, que arquiva, copia, distribui, comenta e traduz as cartas de cientistas da Europa inteira.

Francis André, na obra Libre accès aux savoir, afirma que nessa época surge aquilo que virá a se constituir na base do sistema de comunicação científica moderna: as revistas periódicas científicas. Em 1665, são criados, com alguns meses de intervalo, o Journal des Sçavants e os Philosophical Transactions of the Royal Society of London. O primeiro se dedicava às atividades de ciências e de artes, propondo-se a difundir resumos analíticos de obras recentes, assim como aos elementos da atualidade científica. A revista inglesa dispunha-se a publicar as comunicações originais apresentadas em sessões públicas. Essas publicações foram pioneiras e eram impressas periodicamente, consolidando as comunidades de intelectuais e estabelecendo as primeiras redes de intercâmbio dos avanços científicos.

As revistas científicas desempenham, desde o seu aparecimento, papel primordial na constituição de uma ciência oficial, validada, identificada, verdadeiro capital científico de referência, sobre a qual se apóiam as pesquisas subseqüentes. Em consequiência, tais revistas tornam-se objeto de uma classificação. Portanto, revistas prestigiosas coexistem com revistas de menor ranking. Para um pesquisador publicar um trabalho em uma revista de maior prestígio significa não apenas ser aceito e reconhecido por uma elite, mas, às vezes, ser aceito pelo conselho editorial do periódico. Todo artigo é submetido, antes de sua publicação, à avaliação por seus pares. $\mathrm{O}$ autor, portanto, assume, uma vez que se submete ao regime da reputação científica, a qual guia o funcionamento do sistema de edição científica, o papel de avalista da ciência oficial. 
Da mesma forma que as revistas científicas são utilizadas pelo pesquisador para difundir o saber científico, são também utilizadas para assegurar a sua própria promoção em uma instituição ou comunidade.

\section{O Surgimento de um Ranking de Revistas Científicas}

Nos anos 60, outro ator interveio no cenário da publicação científica: o Institute for Scientific Information [ISI], criado pelo americano Eugene Garfield, que teve a idéia de analisar as citações bibliográficas presentes nos artigos de revistas convenientemente escolhidas e de definir uma base de referência: o Science Citation Index [SCI], referência mundial que define as métricas para classificação das revistas segundo o seu fator de impacto. Esse indicador exprime a visibilidade e a notoriedade de uma revista. Assim, todo artigo publicado em uma revista com forte fator de impacto acaba por transformar o seu autor em autoridade. Não cabe aqui aprofundar o conceito desse indicador. Existem alguns pontos polêmicos, tais como: i) o número de revistas de referência constantes na SCI totaliza menos de 10 mil, pouco se comparado com o total de dezenas de milhares de revistas científicas existentes no mundo (cerca de 80 mil, segundo André, 2005); ii) o ISI é uma instituição norte-americana, cuja tendência é naturalmente privilegiar a ciência produzida em língua inglesa e mais especialmente nos EUA.

O uso generalizado do SCI pela comunidade científica acaba por polarizar a atenção dos editores comerciais sobre as revistas selecionadas pelo SCI, que têm como conseqüência, ao longo dos últimos anos, acelerar, em progressão geométrica, a alta dos preços de assinatura de tais revistas. Percebe-se, assim, que as bibliotecas das instituições de ensino superior não conseguem manter as assinaturas dessas revistas. Essa situação não é privilégio de nossas bibliotecas, mas verifica-se que as bibliotecas de outros países, até mesmo daqueles desenvolvidos, também não conseguem manter essas assinaturas, dificultando o acesso à informação contida nessas revistas por parte da comunidade científica.

\section{Dificuldades de Acesso à Informação Científica}

No passado, o Brasil, por intermédio da Coordenação de Aperfeiçoamento de Pessoal de Nível Superior [Capes], chegou a subsidiar essas assinaturas, mantendo as assinaturas de um conjunto de revistas consideradas importantes para 
as nossas pesquisas, nas várias bibliotecas universitárias e dos institutos de pesquisa. A definição desse conjunto era realizada por meio da avaliação do uso delas, a qual resultava em uma aquisição planificada. Em seguida, da mesma forma como aconteceu em alguns países, começaram a surgir os consórcios, dando origem aos portais de periódicos eletrônicos. Um exemplo dessas iniciativas é o Portal de Periódicos da Capes, que hoje custa aos cofres do governo brasileiro cerca de 30 milhões de dólares. Trata-se de iniciativa importante para o desenvolvimento científico e tecnológico do país, uma vez que esse portal fornece o acesso às principais revistas científicas do mundo, possibilitando aos nossos pesquisadores o seu acesso. O desenvolvimento científico e tecnológico é altamente dependente da informação científica. Trata-se de um processo que gera novas informações que, por sua vez, o realimentam.

Essa solução, entretanto, não atende completamente à comunidade científica, pois o portal não é acessível por todos os segmentos dessa comunidade, além do fato de esses portais não oferecerem todos os títulos importantes para a pesquisa brasileira.

\section{Um Novo Paradigma para a Comunicação Científica}

Com o surgimento das novas tecnologias da informação e da comunicação, novas alternativas de comunicação científica surgiram, provocando alterações nos seus paradigmas. Uma dessas iniciativas foi o Open Archives Initiative [OAI], a partir do qual foram estabelecidos alguns padrões tecnológicos e ideais que se integraram em um processo, visando a facilitar o acesso à informação científica por parte da comunidade científica. Como consequiência dessa iniciativa, surgiu o movimento denominado Open Access to Knowledge and Information in Sciences and Humanities. Várias instituições de pesquisa e países aderiram a esse movimento por meio do estabelecimento de declarações, como a Declaration of Berlin, a Declaration of Bethesda, na Europa, e o Manifesto Brasileiro de Apoio ao acesso livre à Informação Científica no Brasil, lançado em setembro de 2005 pelo Instituto Brasileiro de Informação em Ciência e Tecnologia [Ibict]. Esse movimento surgiu em função das dificuldades encontradas para se ter acesso à informação produzida pela própria comunidade científica. Em outras palavras, o trabalho publicado pelos pesquisadores nem sempre é acessível à comunidade, apesar de o mesmo ter sido financiado com recursos públicos.

A idéia que dá respaldo a esses movimentos é a seguinte: todo resultado de 
pesquisa financiada com recursos públicos deveria estar disponível para acesso público. Nesse sentido, as agências de fomento, os governos dos países, as instituições de pesquisa e os próprios pesquisadores desempenham papel importante para que se consiga mudar o paradigma da comunicação científica tradicional. Além disso, o desenvolvimento econômico, industrial e cultural da sociedade é sustentado pelos conhecimentos científicos acumulados ao longo do tempo. O compartilhamento desse conhecimento, que foi essencialmente produzido no hemisfério Norte, é uma condição necessária, mas não suficiente, para diminuir as desigualdades existentes no mundo. A combinação desses dois fatores, concentração do conhecimento no hemisfério Norte e os custos extorsivos das publicações científicas, proporciona o fenômeno que está sendo conhecido como exclusão cognitiva. Incluem-se, nesse fenômeno, aqueles que não possuem acesso à informação científica, especialmente os pesquisadores de países em desenvolvimento e não desenvolvidos.

Assim, o modelo Open Archives, que surgiu para transformar a comunicação científica, mostra-se útil no suporte das ações de maximização do acesso à informação científica. Ou seja, tais ações não devem ser entendidas como alternativas à comunicação científica. Longe disso, o que o movimento do acesso livre ao conhecimento científico propõe é a utilização desse modelo em prol do acesso livre ao conhecimento, mantendo os mesmos fundamentos da comunicação científica tradicional. Portanto, os pesquisadores continuam publicando os seus trabalhos nas mesmas revistas em que estão acostumados a publicar, mas passam a ter de depositar uma cópia desse trabalho em um repositório institucional da instituição com a qual têm vínculo empregatício.

O movimento do acesso livre à literatura científica propõe duas estratégias para alcançar os seus objetivos: 1) via verde; 2 ) via dourada. A via verde referese ao auto-arquivamento, pelos autores ou seus representantes, de uma cópia de seus papers em um repositório, institucional ou temático, de acesso livre. A via dourada refere-se à publicação de artigos em revistas científicas de livre acesso.

Para tanto, nos EUA e em outros países da Europa, diversos repositórios de acesso livre estão sendo construídos, utilizando o modelo Open Archives. Hoje, os EUA, o Reino Unido e a Alemanha encontram-se, respectivamente, em primeiro, segundo e terceiros lugares em termos da quantidade de repositórios que esses países possuem. O Brasil ocupa atualmente o quarto lugar nesse ranking.

Desde 2000, o Ibict vem absorvendo, internalizando, adequando e desenvolvendo os padrões e ideais estabelecidos pelo modelo Open Archives. A primeira iniciativa empreendida pelo Ibict, utilizando esse modelo, é a Biblioteca Digital de 
Teses e Dissertações [BDTD], a qual integra, atualmente, 64 Instituições de Ensino Superior [IES], mantenedoras de programas de pós-graduação, formando acervo de cerca de $53 \mathrm{mil}^{(2)}$ teses e dissertações defendidas nessas instituições. Trata-se de empreendimento bem-sucedido, que promoveu a formação de uma competência nacional no uso e desenvolvimento dos padrões estabelecidos pelo modelo Open Archives. Os pacotes de software desenvolvidos no âmbito desse empreendimento são Open Source, ou seja, software livre. Graças ao uso desses padrões, as teses e dissertações depositadas na BDTD estão sendo disseminadas pela Universidade do Chile e pela Networked Digital Library of Thesis and Dissertations [NDLTD], a biblioteca mundial de teses e dissertações.

Além dessa iniciativa, o Ibict vem transferindo outra tecnologia, também baseada no mesmo modelo, chamada Sistema Eletrônico de Editoração de Revistas [SEER]. Esse pacote de software permite a construção de revistas científicas eletrônicas na web. Essa iniciativa vem ajudando sobremaneira os editores científicos nacionais na construção de suas revistas científicas eletrônicas. Atualmente, existem cerca de $250^{(3)}$ revistas implementadas por esse pacote de software. A tecnologia e os padrões utilizados por esse pacote permitirão a construção de um catálogo com todos os trabalhos publicados nessas revistas.

Existem, no mundo, mais de 2 mil revistas científicas eletrônicas de acesso livre, além de diversas centenas de repositórios com trabalhos científicos publicados em revistas comerciais. Um exemplo de iniciativa de publicações periódicas científicas de acesso livre no Brasil é o SCIELO, e no exterior, o Directory of Open Access Journals [DOAJ]. Este último indexa cerca de 2.100 revistas científicas eletrônicas, de acesso livre, incluindo aquelas existentes no SCIELO.

O Ibict, com o apoio do Ministério da Ciência e Tecnologia [MCT], obteve, junto à Financiadora de Estudos e Pesquisas [FINEP], financiamento para a construção de um portal de repositórios e periódicos de acesso livre. Esse projeto é na realidade mais do que um simples projeto de portal. Trata-se de programa que envolve diversas ações, além da construção do portal. Nesse programa, está prevista a implementação de uma série de ações que acabam por delinear uma política nacional de acesso livre à informação científica.

\section{Por Que Essa Política?}

Diversos estudos estão sendo realizados com o propósito de comparar o fator de impacto de artigos em regime de acesso livre com relação àqueles que não o são. 
Harnad e Brody (2004) indicam que a maneira de comparar o impacto do acesso livre é não comparar os fatores de impacto de publicações científicas de acesso livre com aquelas que não são de acesso livre, mas, sim, comparar o fator de impacto dos artigos que são de acesso livre com aqueles que não são de acesso livre.

Ainda, segundo Harnad e Brody (2004), esses estudos começam a revelar na era do acesso livre que há surpreendentemente uma nítida diferença, em termos da freqüência com que o artigo é citado: há vantagem impressionante em favor dos artigos, cujos autores os tenham convertido para acesso livre.

$\mathrm{Na}$ área de ciência da computação, os estudos desenvolvidos por Lawrence (2001) já indicavam melhoria considerável nos fatores de impacto entre os artigos de acesso livre e os que não são de acesso livre. Mais recentemente (Brody et al., 2004), estudos realizados na área de física, até 2001, revelaram maiores efeitos que aqueles reportados por Lawrence, na proporção acesso livre / não acesso livre, de 2,5 - 5,8.

Esses estudos já foram realizados nas áreas de ciência da computação, astronomia e física. Outras áreas estão sendo objeto de estudos atualmente.

Esses resultados justificam a necessidade de o Brasil investir na construção de repositórios de acesso livre, de revistas científicas eletrônicas de acesso livre, além de articular uma série de ações que visam à promoção do acesso livre à literatura científica, da mesma forma como vem ocorrendo em vários países.

Para tanto será necessário o estabelecimento de uma série de ações junto às agências de fomento, às universidades e às instituições de pesquisa e, enfim, ao pesquisador. Parte dessas ações está consubstanciada nas recomendações constantes do Manifesto Brasileiro de Apoio ao acesso livre à Informação Científica.

Se hoje o Brasil ocupa o quarto lugar no ranking de países por quantidade de repositórios, a implantação dessa política, aliada à construção do portal, proporcionará ao país galgar novos patamares, disponibilizando volume maior de informação científica à sua comunidade.

Ao contrário do que muitos podem pensar, esse portal e, por conseguinte, essa política não são uma concorrência com o portal de periódicos da Capes. O Ibict entende que o portal de periódicos da Capes tem uma importância ímpar para o desenvolvimento científico e tecnológico do país, uma vez que nele se encontram as principais e mais conceituadas revistas científicas e bases de dados. Portanto o país não pode prescindir da existência desse portal. O custo dele é compatível com 
aquilo que outras bibliotecas no mundo pagam. No entanto tal custo é muito alto, e esse portal, apesar de oferecer ampla gama de periódicos científicos, não é exaustivo. Estima-se que haja, na atualidade, cerca de 80 mil títulos espalhados pelo mundo. Desse total, o portal oferece o acesso a cerca de 10 mil títulos. Isso, porém, deve ser entendido como conseqüência das limitações orçamentárias, e não como deficiência do portal. Afinal, os recursos para essa área são muito escassos.

Em contrapartida, entendemos que o país também não pode ficar à margem dos acontecimentos que vêm ocorrendo no mundo. Existe um movimento que poderá, em futuro próximo, proporcionar a países como o Brasil maior autonomia com relação aos editores científicos comerciais. Trata-se do movimento em prol do acesso livre à informação e ao conhecimento. Em razão desse movimento, países como a Alemanha, o Canadá e a França e os próprios EUA vêm construindo repositórios institucionais e temáticos, nos quais os pesquisadores têm sido estimulados a depositar os seus resultados de pesquisa, em especial aqueles oriundos de estudos financiados com recursos públicos. A iniciativa que ora começamos a construir no Brasil poderá não só internalizar tecnologias e padrões, mas, de fato, dotar o país de maior acessibilidade à informação científica e, conseqüentemente, maximizar a visibilidade de nossa pesquisa.

O estabelecimento de uma política nacional de acesso livre à informação científica provocará mudanças significativas na comunicação científica no país e, principalmente, nas Instituições de Ensino Superior [IES]. Hoje, seria difícil dizer, com exatidão, qual a produção técnico-científica de uma IES. Talvez a plataforma Lattes, construída e hospedada pelo Conselho Nacional de Desenvolvimento Científico e Tecnológico [CNPq], possa dar uma idéia, mas não teria a precisão necessária e não daria acesso aos textos integrais dos trabalhos.

Uma das vertentes que sustenta a missão do Ibict é o registro e a disseminação da produção científica brasileira. Há alguns anos, o Instituto teve que abdicar dessa vertente em função do cenário tecnológico existente nos anos 80, o qual contemplava excessiva centralização e dificuldades de comunicação e processamento de dados. Com a convergência das tecnologias da informação e da comunicação, além do estabelecimento da política aqui mencionada, o Instituto conta, hoje, com uma caixa de ferramentas capaz de retomar esse papel.

Nesse contexto, as bibliotecas das IES e das unidades e pesquisa desempenharão papel importante. A mudança de paradigma na comunicação científica passa por essas bibliotecas. Essas deveriam ser mais do que um simples depósito de livros e revistas, mas deveriam liderar, de fato, o estabelecimento de uma política informacional em suas respectivas instituições. Ao assumir esse papel, as biblio- 
tecas poderão tornar-se o depositário legal de toda a produção técnico-científica da sua instituição.

O Ibict, ao longo dos últimos quatro anos, vem trabalhando junto às IES, mais especificamente com as suas bibliotecas, e tem logrado a instalação de bibliotecas digitais locais de teses e dissertações. No entanto o contingente de atores é bem maior, incluindo não apenas a comunidade discente, mas também os professores e pesquisadores. Artigos são publicados, livros inteiros ou mesmo capítulos de livros, relatórios técnicos, pareceres e projetos são produzidos. Essa produção, contudo, não está disponível para a comunidade. Além disso, existem trabalhos de conclusão de cursos de excelente qualidade que não têm a devida divulgação. As teses e dissertações, por sua vez, representam apenas pequena parte do que se produz em uma universidade. É necessário que essas instituições sejam estimuladas a criar os seus repositórios e que toda essa documentação seja disponibilizada para a comunidade científica e tecnológica de forma livre.

É com essa visão que o Ibict construirá o Portal de Repositórios e Periódicos de acesso livre e coordenará a implantação da Política Nacional de acesso livre à Literatura Científica.

\section{Considerações Finais}

As iniciativas aqui apresentadas fazem parte do cenário que se desenha internacionalmente. Com os custos extorsivos das publicações periódicas científicas, uma nova ordem mundial está se impondo: a criação de repositórios institucionais nas universidades e instituições de pesquisas aliada a um mandato legal que obriga os pesquisadores a depositarem os seus resultados de pesquisa publicados em revistas científicas reconhecida nacional e internacionalmente. Assim, o modelo tecnológico que se apresenta como suporte dessas ações do movimento de livre acesso ao conhecimento científico é o de Arquivos Abertos (Open Archives). É importante salientar que o que se está propondo não é a criação de um modelo alternativo de comunicação científica, mas pura e simplesmente um modelo de sustentabilidade da pesquisa científica. Trata-se de um modelo que proporcionará aos pesquisadores o acesso livre à literatura científica, principal insumo para o desenvolvimento de suas pesquisas.

A implantação desse modelo proporcionará, além da sustentabilidade ao desenvolvimento científico dos países, em particular nos países em desenvolvimento e em países não desenvolvidos, os seguintes resultados: 
. maximização da visibilidade das pesquisas científicas;

. internacionalização da informação científica produzida localmente;

. maior compartilhamento do conhecimento científico;

. redução da exclusão cognitiva;

. redução das desigualdades sociais.

Certamente, esses resultados não serão imediatos. Como se trata de um processo inovador e que promove a mudança de paradigmas no fluxo da informação científica haverá dificuldades, além do impacto econômico que essas ações proporcionarão aos vários setores envolvidos.

Verifica-se que, devido ao fato de as propostas do movimento do acesso livre à literatura científica serem baseadas no uso das tecnologias da informação e da comunicação, forçosamente a produção científica local e mundial de acesso livre ficarão disponíveis para acesso na rede mundial de computadores. Esse fato conduzirá à internacionalização de toda essa produção científica mundial.

É oportuno ressaltar que as propostas do movimento do acesso livre à literatura científica não representam riscos de pirataria ou plágio, ou mesmo de roubo de patentes. O que se propõe fazer é maximizar a visibilidade daquilo que os autores já fazem hoje, que é publicar em uma revista científica, especialmente aqueles publicados em revistas científicas de alto nível. Portanto os riscos existentes são os mesmos que hoje existem; cabe aos autores ter cuidado com aquilo que escrevem.

\section{Notas}

${ }^{1}$ Este texto foi publicado no livro de Toutain, L. M. B. B. (Org.). (2007). Para entender a ciência da informação. Salvador: EDUFBA. (Saladeaula, 6).

${ }^{2}$ Esse número foi visto em 17/09/2007, mas cresce diariamente e se desatualiza rapidamente.

${ }^{3}$ Número de revistas existente em 17/09/2007. 


\section{ReferênCIAS Bibliográficas}

André, F. (2005).

Libre accès aux savoirs. Paris: Futuribles.

Brody, T.,

Stamerjohanns, H.,

Harnad, S.,

Gingras, Y.,

Vallieres, F., \&

Oppenheim, C. (2004, February).

The effect of open access on citation impact. National Policies on Open Access (OA) Provision for University Research Output: an International meeting. Southampton University, Southampton UK. Recuperado em 18 setembro, 2007, de http:// opcit.eprints.org/feb19prog.html
Harnad, S., \&

Brody, T. (2004).

Comparing the impact of open access (OA) vs. Non-OA articles in the same journals. Dlib Magazine, 10(6). Recuperado em 19 setembro, 2007, de http://www.dlib.org/dlib/june04/ harnad/06harnad.html\#Brody

Lawrence, S. (2001).

Free online availability substantially increases a paper's impact: nature webdebates. Recuperado em 19 setembro, 2007, de http:// www.nature.com/nature/debates/eaccess/Articles/lawrence.html

Meadows, A. J. (1999).

A comunicação científica. Brasília: Briquet de Lemos Livros. 